\title{
Enfermedad causada por COVID-19
}

\section{IIIness caused by COVID-19}

Acad. Dr. Jesús Carlos Briones-Garduño,* Acad. Dr. Raúl Carrillo-Esper, Acad. Dra. Guadalupe Guerrero-Avendaño*, Dr. José Meneses-Calderón, ${ }^{\S}$ Dr. Ángel Augusto Pérez-Calatayud,* Dr. Rubén Castorena-de Alba, ${ }^{\S}$ Dr. Carlos Gabriel Briones-Vega," Acad. Dr. Manuel Díaz de León-Ponceף

Citar como: Briones-Garduño JC, Carrillo-Esper R, Guerrero-Avendaño G, Meneses-Calderón J, Pérez-Calatayud ÁA, Castorena-de Alba R, y cols. Enfermedad causada por COVID-19. Rev Mex Anest. 2021; 44 (1): 70-72. https://dx.doi. org/10.35366/97781

E stamos viviendo una pandemia mundial causada por un coronavirus conocido como SARS-CoV-2 que la OMS nombró COVID-19, que se manifiesta con diferentes respuestas clínicas en cada ser humano:

- Asintomático (portador potencialmente infectante)

- Enfermedad leve que se atiende con tratamiento domiciliario

- Enfermedad moderada que requiere tratamiento hospitalario

- Evento agudo grave de atención en cuidados intensivos

El diagnóstico se hace con base en la toma del exudado nasofaríngeo (hisopado) y se procesa mediante la técnica de genética molecular RCP-RT, que inclusive puede cuantificar la carga viral.

Aparentemente, la posible explicación para este abanico de posibilidades es genéticomultifactorial, entre los que destacan:

- Tipo de virus: ya se han documentado múltiples replicaciones del virus nativo.

- Carga viral: es decir, el inóculo y posiblemente el tiempo de exposición al mismo.

- Respuesta inmune: que es individual, tanto humoral con generación de IgM e IgG, medible con técnicas electroluminiscencia, y también la respuesta celular mediada por linfocitos, de los cuales destacan CD3, CD4 y CD8, que se pueden cuantificar por citometría de flujo.

- Estado inflamatorio: de repercusión múltiple como respuesta del huésped a esta infección viral, se ha descrito una tormenta de citocinas y quimiocinas que magnifican el daño alveolar difuso con desarrollo de síndrome de insuficiencia respiratoria, que requiere apoyo con ventilación mecánica, en toda la microcirculación trombosis que justifica el uso de heparina y lesión multiorgánica, lo que implica apoyo multiorgánico en cuidados intensivos.

- Edad y el sexo: del individuo al parecer en relación con su respuesta inmune, afectando predominantemente a población masculina mayor de 50 años.

- Comorbilidades preexistentes: destacando obesidad, como un modelo de proceso inflamatorio crónico, hipertensión arterial explicada por el desarrollo de receptores ACE-2, que es el sitio donde se ancla la proteína $\mathrm{S}$ de la espícula del coronavirus, y la diabetes presumiblemente por ser un estado de inmunocompromiso ${ }^{(1)}$.

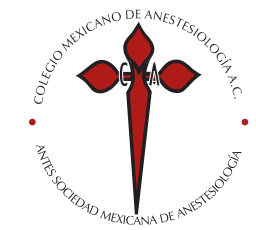

\footnotetext{
* Hospital General de México, «Dr. Eduardo Liceaga».

‡ Instituto Nacional de

Rehabilitación.

§ Hospital «Mónica Pretelini Sáenz».

$\|$ Instituto de Genética e Infertilidad.

" Academia Nacional de Medicina

y Academia Mexicana de Cirugía.

Correspondencia:

Acad. Dr. Jesús Carlos

Briones-Garduño

Hospital General de México,

«Dr. Eduardo Liceaga»

Dr. Balmis Núm. 148, Col. Doctores,

Alcaldía Cuauhtémoc, C.P. 06720.

Tel. 5527892000 ext. 1605

E-mail:

drcarlosbriones@yahoo.com.mx

Recibido para publicación:

27-11-2020

Aceptado para publicación:

12-01-2021
} 
Medidas generales y farmacológicas con las que contamos:

- El portador asintomático: resaltamos la importancia de identificarlos porque, de no hacerlo, estará infectando en forma exponencial a muchas personas, al identificarlo se aísla hasta ser negativo, aquí radica la importancia del uso obligatorio de cubrebocas, mínimo de tres capas, la sana distancia que implica evitar reuniones de muchas personas y, sobre todo, el lavado de manos frecuente con agua y jabón y el uso de gel-alcohol.

- Enfermedad leve: además de las medidas generales como uso de cubrebocas, lavado de manos y uso de gel-alcohol, la atención en su domicilio, implica aislamiento del resto de sus familiares, las manifestaciones consisten en fiebre, rinitis, odinofagia, cefalea, mialgias o artralgias, despeñes diarreicos, cansancio, o bien, con datos típicos del virus como pérdida del olfato y gusto. Para el tratamiento recomendamos utilizar paracetamol para aliviar las molestias descritas, pero también la utilización de nitazoxanida e ivermectina, ambos antiparasitarios, que han demostrado in vitro en animales de laboratorio que evitan la replicación de múltiples virus donde se incluyen los coronavirus como el SARS-CoV-2, con esto buscamos disminuir la carga viral, también se utiliza la vitamina $\mathrm{D}$, que se conoce estimula el sistema inmune celular. El paciente debe vigilarse en especial con toma de temperatura y oximetría de pulso y, en caso de desaturación y datos de insuficiencia respiratoria, tomar otras medidas.

- La enfermedad moderada: es aquella que progresa con datos de desaturación y/o insuficiencia respiratoria que requiere apoyo con oxígeno suplementario, es necesario en estos casos la toma de Rx con telerradiografía de tórax que puede demostrar infiltrados bronquio-alveolares, se considera que la TAC es el estudio ideal para visualizar todo el parénquima pulmonar, corazón y grandes vasos para delimitar el daño cardiopulmonar y decidir junto con el resultado de gasometría si sólo requiere oxígeno suplementario con puntas nasales, mascarilla de reservorio o mascarilla para ventilación no invasiva, o bien, la ventilación mecánica invasiva, también se requiere la vigilancia con la cuantificación de por lo menos cuatro moléculas para evaluar respuesta inflamatoria como son: dímero $\mathrm{D}, \mathrm{LDH}$, proteína $\mathrm{C}$ reactiva y ferritina, resulta particularmente útil titular niveles de vitamina $\mathrm{D}$ (ya que los pacientes graves tienen niveles subnormales) y cuantificar respuesta humoral con IgG, así como respuesta celular con CD3, CD4 y CD8, dependiendo y evaluando en forma individual todos los resultados; el tratamiento implica además de nitazoxanida, ivermectina, vitamina $\mathrm{D}$, paracetamol, iniciar si está disponible remdesivir como antiviral, dexametasona para minimizar la respuesta inflamatoria, heparina para mejorar la microcirculación y antiagregantes plaquetarios, como ácido acetil salicílico o clopidogrel y dependiendo de la evolución de cuadro respiratorio será candidato a cuidados intensivos $^{(2-5)}$.

- El paciente con evento agudo: por insuficiencia respiratoria o falla orgánica múltiple debe pasar a la Unidad de Cuidados Intensivos, donde se manejará con apoyo multiorgánico como ventilación mecánica invasiva con pronación alternada, sedación-relajación, apoyo inotrópico o vaso-activo, en ocasiones hemodiálisis, requiere monitoreo continuo, tanto electrónico como de laboratorio y gabinete, farmacológicamente, además de lo descrito para el paciente con infección moderada se contempla el uso de antibióticos de amplio espectro iniciando con un macrólido como es la azitromicina, ya que $30 \%$ de estos pacientes se colonizan de bacteria, por lo que se requieren multicultivar para dirigir la terapia antibacteriana, optimizar el uso de heparina, en especial la heparina convencional, el control de la respuesta inflamatoria a base de dexametasona. Se ha intentado con resultados no concluyentes el uso de plasma híperinmune y la misma plasmaféresis, también medicamentos como bloqueadores de interleucina 6 con anticuerpos monoclonales (tocilizumab), y fármacos antifibróticos como la colchicina. Moléculas prometedoras que puedan bloquear el sitio de anclaje del virus a nivel de receptor celular como el maraviroc en combinación con un antiviral favipiravir, o bien, fármacos como la pirfenidona para minimizar la fibrosis pulmonar que causará hipertensión, así la misma vacuna de la cual hay múltiples opciones comerciales, constituyen una esperanza para ser considerada en los ensayos clínicos y su utilización a corto-mediano plazo ${ }^{(6-8)}$. 


\section{REFERENCIAS}

1. Guallar MP, Meiriño R, Donat-Vargas C, Corral O, Jouvé N, Soriano V. Inoculum at the time of SARS-CoV-2 exposure and risk of disease severity. Int J Infect Dis. 2020;97:290-292.

2. Beigel JH, Tomashek KM, Dodd LE, Mehta AK, Zingman BS, Kalil $\mathrm{AC}$, et al. Remdesivir for the treatment of Covid-19 - final report. N Engl J Med. 2020;383:1813-1826.

3. Mahmoud DB, Shitu Z, Mostafa A. Drug repurposing of nitazoxanide: can it be an effective therapy for COVID-19? J Genet Eng Biotechnol. 2020;18:35.

4. Espreafico Junior CR, do Nascimento Antonio MV, Imperador CHL, Chin CM, Longhin Bosquesi P. Remdesivir, nitazoxanida e ivermectina na COVID-19. J Med. 2020;1:74-80.

5. Meneses Calderón J, Figueroa Flores MDR, Paniagua Coria L, Briones Garduño JC, Meneses Figueroa J, Vargas Contretas MJ, et al. Nitazoxanide against COVID-19 in three explorative scenarios. J Infect Dev Ctries. 2020;14:982-986. doi: 10.3855/jidc.13274.

6. Seifrad S. Pirfenidona: a novel hypothetical treatment for COVID-19. Medical Hypotheses. 2020;144:110005.

7. Ferrara F, Granata G, Pelliccia C, La Porta R, Vitiello A. The added value of pirfenidone to fight inflammation and fibrotic state induced by SARS-CoV-2: anti-inflammatory and anti-fibrotic therapy could solve the lung complications of the infection? Eur J Clin Pharmacol. 2020;76:1615-1618.

8. Guérin C, Albert RK, Beitler J, Gattinoni L, Jaber S, Marini JJ, et al. Prone position in ARDS patients: why, when, how and for whom. Intensive Care Med. 2020;46:2385-2396. 